\title{
Free Radical-Scavenging Properties and Antioxidant Activity of Fractions from Cranberry Products
}

\author{
Stéphane Caillet ${ }^{1}$, Guillaume Lorenzo ${ }^{1}$, Jacinthe Côté ${ }^{1}$, Jean-François Sylvain ${ }^{2}$, Monique Lacroix $^{1 *}$ \\ ${ }^{1}$ Research Laboratories in Sciences Applied to Food, Nutraceutical and Functional Food Institute, INRS-Institut Armand-Frappier, \\ Université du Québec, Laval, Canada; ${ }^{2}$ Atoka Cranberries Inc., Manseau, Canada. \\ Email: *Monique.lacroix@iaf.inrs.ca
}

Received November $10^{\text {th }}, 2011$; revised January $9^{\text {th }}, 2012$; accepted January $16^{\text {th }}, 2012$

\begin{abstract}
Lipid peroxidation inhibition capacity and antiradical activity were evaluated in HPLC fractions of different polarity obtained from two cranberry juices and three extracts isolated from frozen cranberries and pomace containing anthocyanins, water-soluble and apolar phenolic compounds, respectively. Compounds with close polarities were collected to obtain between three and four fractions from each juice or extract. The cranberry phenols are good free radical-scavengers, but they were less efficient at inhibiting the lipid peroxidation. Of all the samples tested, the intermediate polarity fraction of extract rich in apolar phenolic compounds of fruit presented the highest antiradical activity while the most hydrophobic fractions of the anthocyanin-rich extract from fruit and pomace appeared to be the most efficient at inhibiting the lipid peroxidation. The antioxidant or pro-oxidant activity of fractions increased with the concentration. The phenol polarity and the technological process to manufacture cranberry juice can influence the antioxidant and antiradical activities of fractions.
\end{abstract}

Keywords: HPLC Fractions; Cranberry Juices; Phenolic Extracts; Free Radical Scavenging Capacity; Antioxidant Activity

\section{Introduction}

Stresses, physical damage, viral infection, cytotoxic or carcinogenic compounds, as a consequence of chemical or biological aggression, may cause peroxidation of cell membrane lipids and liberation of toxic substances, such as free radicals [1]. Studies concerning the relationship between the morbidity due to cancer and heart diseases and the consumption of fruits and vegetables indicated that polyphenols present in large amount in fruits and vegetables have a significant impact on the morbidity decrease from these diseases [2]. Fruits, including berries, are one of the most important sources of phenolic compounds in our diets. Especially hydroxybenzoic and hydroxycinnamic acid derivatives, anthocyanins, flavonols, catechins, and tannins, hydrolyzable or condensed, are frequently present [3]. Many of these compounds exhibit a wide range of biological effects, including antioxidant, antimicrobial, anti-inflammatory, and vasodilatory actions [4]. Phenolic extracts of berries (blackberries, red raspberries, sweet cherries, blueberries, and strawberries) inhibited human low-density lipoprotein (LDL) and liposome oxidation [5]. Berries have also shown a remarka-

${ }^{*}$ Corresponding author. bly high scavenging activity toward chemically generated active oxygen species [6]. Antioxidants can interfere with the oxidation process by reacting with free radicals, chelating catalytic metals, and also by acting as oxygen scavengers [7].

The antioxidant properties of cranberries are documents in the literature and cranberries are ranked one of the highest antioxidant activities among many other fruits [8]. Cranberry phenolics have been shown to have free radical-scavenging properties against superoxide radical $\left(\mathrm{O}_{2}^{-}\right)$, hydrogen peroxide $\left(\mathrm{H}_{2} \mathrm{O}_{2}\right)$, hydroxyl radicals $(\cdot \mathrm{OH})$, and singlet oxygen $\left({ }^{1} \mathrm{O}_{2}\right)$, and they can also inhibit lipid peroxidation, as well as protein and lipid oxidation in liposomes [6]. The anthocyanin pigments responsible for the fruit brilliant red color and are among the princepal antioxidant constituents [5]. Other phytochemicals found in cranberries (flavonols, flavanols and benzoic and cinnanmic acid derivatives) have attracted a great deal of attention because of their antioxidant activity $[8,9]$. Porter et al. [10] demonstrated that proanthocyanidin found in cranberry inhibits the oxidation of human LDL catalyzed by copper ions in vitro. Although, the antioxidants of cranberry products in lipid systems and the free radical-scavenging capacity have been studied, investigations 
on the fractions of phenolic compounds isolated from cranberry products are very scarce $[10,11]$. Also, there has been an increasing interest in exploring new antioxidants of natural origins because of the potential toxicity of synthetic antioxidants and consumers' preference [11]. In addition, some fractions of cranberry polyphenols could present significant potential benefits for human health $[12,13]$.

Thus, the aim of the present study was to evaluate the antioxidant and antiradical activities of fractions of different polarity obtained from two cranberry juices (clarified juice and juice concentrate) and three extracts from cranberry fruits and pomace containing water-soluble and apolar phenolic compounds, and anthocyanins. In this work, an HPLC method for the separation of fractions was established, and a rapid colorimetric method for measurement of free radical-scavenging capacity was applied and a non-enzymatic method of liposome peroxidation was used for evaluating the ability of a sample to inhibit oxidation and to prevent damage to cellular membranes.

\section{Materials and Methods}

\subsection{Raw Material and Cranberry Processing}

Frozen cranberries (Vaccinium macrocarpon) and three main cranberry processing products (pomace, clarified juice and juice concentrate (final product)) were provided by Atoka Cranberries Inc. (Manseau, QC, Canada) and were stored at $-80^{\circ} \mathrm{C}$ until used. The initial processing step to make juice involves reducing frozen cranberries to a mash using a fruit mill. Then, the raw juice recovery from mash was done using a fruit press at 1.90 bar. During the juice pressing step, high amounts of press cake were obtained: cranberry pomace is the main byproduct of the cranberry processing industry. It is composed primarily of skin, seeds, and stems left over after pressing the fruit for juice. During the filtering process, a cross-flow membrane filtration was used to remove colloids and generate a clear juice from raw juice. Then the clarified juice was concentrated by evaporation to obtain a juice concentrate at $50^{\circ}$ brix.

\subsection{Extraction of Phenolic Compounds and Sample Preparation}

The extraction conditions employed were as mild as possible to avoid oxidation, thermal degradation and other chemical and biochemical changes in the sample. Extraction of phenolic compounds from frozen cranberries and pomace was achieved according to three methods using solvents of different graded polarity for the recovery of specific classes of phenols which have different solubility. The most water soluble phenolic compounds were extracted with water/methanol $(85: 15, \mathrm{v} / \mathrm{v})[14]$, the most apolar phenolic compounds (flavonols, flavan-3-ols and proanthocyanidins) were extracted with acetone/methanol/ water $(40: 40: 20, \mathrm{v} / \mathrm{v})$, modified from a method described by Neto et al. [15], and the anthocyanins were extracted with methanol/water/acetic acid $(85: 15: 0.5, \mathrm{v} / \mathrm{v} / \mathrm{v})$ as described by $\mathrm{Wu}$ and Prior [16]. Frozen cranberries or pomace were crushed at $4^{\circ} \mathrm{C}$ for $40 \mathrm{~s}$ in a Waring commercial blender (Waring Laboratory, Torrington, CT) to obtain a fine powder. Immediately after crushing fruit, extractions have been performed at $4^{\circ} \mathrm{C}$ under agitation and nitrogen for $40 \mathrm{~min}$ by macerating of $300 \mathrm{~g}$ of the fruit powder with the extracting solvents. Three successive extractions in each extracting solvent were performed using the same procedure. The first extraction was done using $700 \mathrm{~mL}$ of solvent, but for the two last ones, 500 $\mathrm{mL}$ was used instead. The solvent containing the phenollic compounds was recuperated after each extraction and the solvents from the successive extractions were combined, then filtered on Whatman paper $n^{\circ} 4$ (Fisher Scientific, Nepean, ON, Canada). The filtrate was concentrated by evaporation of solvent using the SpeedVac Automatic evaporation system (Savant System, Holbrook, NY), then dry matter was determined by freeze-drying the extracts for $48 \mathrm{~h}$ with a Virtis Freeze mobile $12 \mathrm{EL}$ (The Virtis Co., Gardiner, NY), and stored at $-80^{\circ} \mathrm{C}$ until used.

\subsection{HPLC-DAD Fractionation of Extracts and Juices}

The HPLC analyses were performed on a ProStar 230 (Varian Canada Inc., Mississauga, ON, Canada), equipped with a ternary pump delivery system, a Rheodyne injection valve $(500 \mu \mathrm{L}$ capacity, Waters Ltd., Dorval, QC, Canada) and a ProStar 330 diode-array UV-Vis detector (Varian); integration and data elaboration were performed using Star Chromatography Workstation software (Varian). A Zorbax SB-C $18,5 \mu \mathrm{m}, 9.4 \times 250 \mathrm{~mm}$ (Agilent Technologies Canada Inc, Mississauga, ON, Canada) column was used. All solvents were filtered with a $0.45 \mu \mathrm{m}$ Millipore (Millipore Canada Ltd., Etobicoke, ON, Canada) filter disk and degassed with helium. A gradient elution was carried out using the following solvent systems: mobile phase A, double-distilled water/acetic acid (97/3, $\mathrm{v} / \mathrm{v})$; mobile phase B, methanol/acetic acid $(97 / 3, \mathrm{v} / \mathrm{v})$. The linear gradient elution system was: $85 \%-0 \% \mathrm{~A}$ from 0 to $65 \mathrm{~min}$, keeping $100 \% \mathrm{~B}$ for $10 \mathrm{~min}$, returning to $85 \% \mathrm{~A}$, followed by equilibration for $10 \mathrm{~min}$ before injection. For each sample, $500 \mu \mathrm{L}$ were injected after filtration through a $0.45 \mu \mathrm{m}$ filter disk. The flow rate was $3 \mathrm{ml} \cdot \mathrm{min}^{-1}$ and the detection was achieved by photodiode array $(250 \mathrm{~nm}-550 \mathrm{~nm})$. Between three and four fractions per extract or juice were recovered (Table 1). The fractions were defined to obtain well delimited peaks 
Table 1. Times of elution and solvent percentages used for HPLC-DAD fractionation ${ }^{\mathrm{a}}$ of cranberry juices and three extracts from cranberry fruits and pomace.

\begin{tabular}{|c|c|c|c|}
\hline Sample ${ }^{b}$ & Fractions & Time (min) & Solvent A/Solvent B $(\%)^{\text {cd }}$ \\
\hline \multirow{4}{*}{ Fruit E1 } & 1 & $0-13$ & $85 / 15-68 / 32$ \\
\hline & 2 & $13-27$ & $68 / 32-50 / 50$ \\
\hline & 3 & $27-45$ & $50 / 50-26 / 74$ \\
\hline & 4 & $45-65$ & $26 / 74-0 / 100$ \\
\hline \multirow{3}{*}{ Fruit E2 } & 1 & $0-10$ & $85 / 15-72 / 28$ \\
\hline & 2 & $10-38$ & $72 / 28-35 / 65$ \\
\hline & 3 & $38-65$ & $35 / 65-0 / 100$ \\
\hline \multirow{4}{*}{ Fruit E3 } & 1 & $0-5$ & $85 / 15-78 / 22$ \\
\hline & 2 & $5-25$ & $78 / 22-52 / 48$ \\
\hline & 3 & $25-37$ & $52 / 48-37 / 63$ \\
\hline & 4 & $37-65$ & $37 / 63-0 / 100$ \\
\hline \multirow{4}{*}{ Pomace E1 } & 1 & $0-13$ & $85 / 15-68 / 32$ \\
\hline & 2 & $13-27$ & $68 / 32-50 / 50$ \\
\hline & 3 & $27-45$ & $50 / 50-26 / 74$ \\
\hline & 4 & $45-65$ & $26 / 74-0 / 100$ \\
\hline \multirow{4}{*}{ Pomace E2 } & 1 & $0-15$ & $85 / 15-65 / 35$ \\
\hline & 2 & $15-31$ & $65 / 35-44 / 56$ \\
\hline & 3 & $31-46$ & $44 / 56-25 / 75$ \\
\hline & 4 & $46-65$ & $25 / 75-0 / 100$ \\
\hline \multirow{3}{*}{ Pomace E3 } & 1 & $0-15$ & $85 / 15-65 / 35$ \\
\hline & 2 & $15-33$ & $65 / 35-42 / 58$ \\
\hline & 3 & $33-65$ & $42 / 58-0 / 100$ \\
\hline \multirow{4}{*}{ Clarified juice } & 1 & $0-13$ & $85 / 15-68 / 32$ \\
\hline & 2 & $13-27$ & $68 / 32-50 / 50$ \\
\hline & 3 & $27-45$ & $50 / 50-26 / 74$ \\
\hline & 4 & $45-65$ & $26 / 74-0 / 100$ \\
\hline \multirow{4}{*}{ Juice concentrate } & 1 & $0-13$ & $85 / 15-68 / 32$ \\
\hline & 2 & $13-27$ & $68 / 32-50 / 50$ \\
\hline & 3 & $27-45$ & $50 / 50-26 / 74$ \\
\hline & 4 & $45-65$ & $26 / 74-0 / 100$ \\
\hline
\end{tabular}

${ }^{\mathrm{a}}$ The fractions were defined to obtain well delimited peaks : one major peak or several peaks with similar polarity (Figure 1). ${ }^{\mathrm{b}} \mathrm{E} 1, \mathrm{E} 2$ and E3 are three extracts from cranberry fruits and cranberry pomace. E1: the most watersoluble phenolic compounds extracted with water/methanol $(85 / 15, \mathrm{v} / \mathrm{v})$; E2: the most apolar phenolic compounds extracted with acetone/methanol/water (40/40/20, v/v); E3: anthocyanins extracted with methanol/water/acetic acid $(85 / 14.5 / 0.5, \mathrm{v} / \mathrm{v} / \mathrm{v}) .{ }^{\mathrm{c}} \mathrm{A}$ linear gradient was carried out between solvent A (water/acetic acid, 97/3, v/v) and the solvent B (methanol/acetic acid, 97/3, $\mathrm{v} / \mathrm{v}$ ) for $65 \mathrm{~min}$. ${ }^{\mathrm{d}}$ After lyophilization, fractions were re-dissolved in their corresponding solvent of fractionation (average percentage) to evaluate their functional properties.

(one major peak or several peaks with similar polarity) (Figure 1) and standard phenolic compounds were used to evaluate the phenolic content of fractions: standards of p-coumaric acid, caffeic acid, gallic acid, chlorogenic acid, cyanidin 3-galactoside, cyanidin 3-arabinoside, peonidin 3-galactoside, peonidin 3-arabinoside, myricetin 3-galactoside, myricetin 3-arabinoside, quercetin 3-galactoside, quercetin 3-arabinoside and proanthocyanidins (epicatechin units) with degrees of polymerization (DP) of 5 and 6 were purchased from Sigma-Aldrich (Oakville, ON, Canada) and Indofine Inc. (Hillsborough, NJ). The solvent was then removed under nitrogen and dry matter was determined by freeze-drying the fractions for $48 \mathrm{~h}$, and stored at $-80^{\circ} \mathrm{C}$ until used. Prior to the experiment, the freeze-dried fractions were weighed and redissolved in their fractionation solvent to a specified volume.

\subsection{Total Phenol Concentration}

Total phenolic compound content in each fraction from cranberry extracts or juices was determined by spectrophotometry (absorbance at $760 \mathrm{~nm}$ ) according to the Folin-Ciocalteu procedure [17]. Total phenolic compound content of samples was estimated from a calibration curve $\left(r^{2}=0.9986\right)$ by plotting known solutions of gallic acid $(10,20,40,60,80,100$ and $500 \mu \mathrm{g} / \mathrm{mL})$.

\subsection{Determination of Free Radical-Scavenging Capacity}

Free radical scavenging capacity of each fraction from cranberry extracts or juices was evaluated following a modified procedure of the DPD (N,N-diethyl-p-phenylenediamine) (Sigma-Aldrich Ltd, Oakville, ON, Canada) colorimetric method, as reported by Caillet et al. [18]. Two hundred (200) $\mu \mathrm{L}$ of sample $(312.5 \mu \mathrm{g} / \mathrm{ml}$ in final concentration) were added in a cell containing $3 \mathrm{~mL}$ of $0.15 \mathrm{M} \mathrm{NaCl}$ and submitted to electrolysis for $1 \mathrm{~min}$ (10 mA DC, $400 \mathrm{~V}$ ) using a power supply (Bio-Rad, model 1000/500, Mississauga, ON, Canada). After electrolysis, a volume of $200 \mu \mathrm{L}$ of solution was sampled and added to $2 \mathrm{ml}$ of DPD solution $(25 \mathrm{mg} / \mathrm{mL})$. The generated oxidative species (superoxide anion $\left(\mathrm{O}_{2}^{-}\right)$, singlet oxygen $\left({ }^{1} \mathrm{O}_{2}\right)$ and $\mathrm{OH}$ radicals) and their by-products (hydrogen peroxide $\left(\mathrm{H}_{2} \mathrm{O}_{2}\right)$ and hypochlorite ion $\left.\left(\mathrm{OCl}^{-}\right)\right)$react instantly with DPD, producing a red coloration that can be measured at $515 \mathrm{~nm}$ using a DMS 100S spectrophotometer (Varian Canada Inc., Mississauga, ON, Canada). The antiradical activity describes the capacity of polyphenols to inhibit the accumulation of oxidative species (able to oxidize DPD) and consequently the red coloration at 515 $\mathrm{nm}$. The reaction advancement was quantified using the non-electrolyzed $\mathrm{NaCl}$ solution (no oxidative species, ascribed to $100 \%$ scavenging) and the electrolyzed $\mathrm{NaCl}$ solution ( $0 \%$ scavenging, in the absence of any antioxidants). The scavenging percentage was calculated according to the following equation:

$$
\text { Scavenging }(\%)=100-\left[\left(\mathrm{OD}_{\text {sample }} / \mathrm{OD}_{\text {control }}\right) \times 100\right]
$$



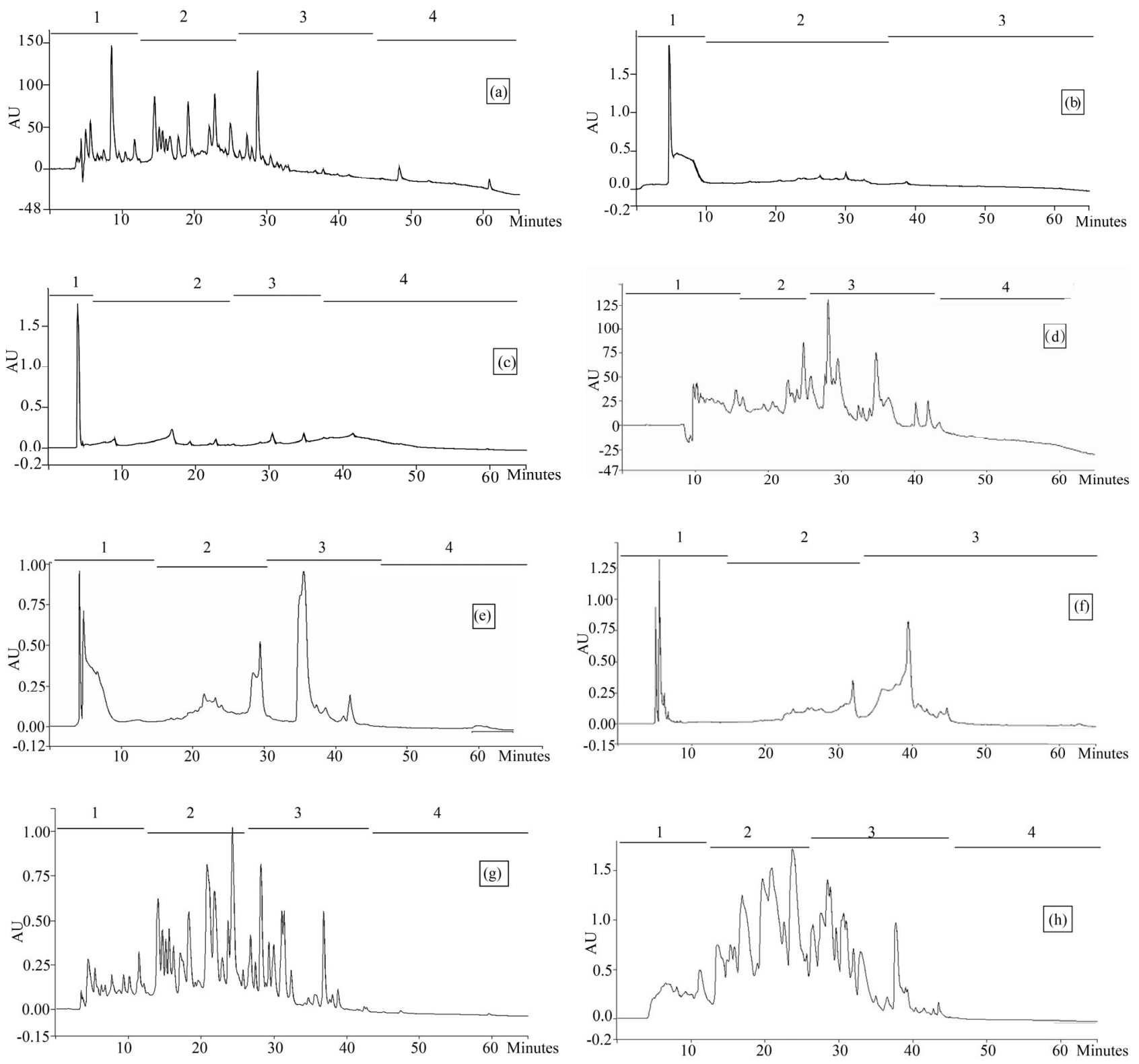

Figure 1. Chromatogram obtained from cranberry juices and three extracts of cranberry fruits and pomace on a Zorbax SB-C $_{18}$ column (250 × 9.4 mm D.I.). Fruit E1 (a), fruit E2 (b), fruit E3 (c), pomace E1 (d), pomace E2 (e), pomace E3 (f), clarified juice (g) and juice concentrate (h). E1, E2 and E3 are three extracts from cranberry fruits and cranberry pomace. E1: the most water-soluble phenolic compounds extracted with water/methanol (85/15, v/v); E2: the most apolar phenolic compounds extracted with acetone/methanol/water (40/40/20, v/v); E3: anthocyanins extracted with methanol/water/acetic acid (85/14.5/0.5, v/v/v). A linear gradient was carried out between solvent A (water/acetic acid, 97/3, v/v) and the solvent B (methanol/acetic acid, 97/3, v/v) for $65 \mathrm{~min}$. The DAD was set at 220 - $550 \mathrm{~nm}$. Between three and four fractions (\#1 - 4) of different polarities were separated from each extract or juice.

where $\mathrm{OD}_{\text {control }}$ represents the $\mathrm{OD}$ of electrolyzed solution in the absence of sample. In fact, OD is directly related to the degree of oxidation of DPD reagent by the oxidative species. Thus extracts or juice able to reduce completely the level of reactive oxidative species will have a $100 \%$ scavenging capacity.

The antiradical activity of extracts and juice was estimated from calibration curve $\left(r^{2}=0.9973\right)$ constructed by plotting known solutions of Trolox ${ }^{\circledR}$ (6-hydroxy-2,5,7, 8-tetramethylchroman-2-carboxylic acid (Sigma-Aldrich Ltd); 0.8, 1.6, 2.4, 3.2, and 4.0 mM) against \% scavenging capacity. Then, data were reported to the quantity of dry matter of each sample and the quantity of phenolic compounds and results were expressed as $\mathrm{mM}$ Trolox ${ }^{\circledR}$ equivalent/mg of dry matter and $\mathrm{mM}$ Trolox ${ }^{\circledR}$ equivalent (TE)/mg of phenol. 


\subsection{Determination of the Lipid Peroxidation Inhibition Capacity}

The determination of the antioxidant activity of each fraction from cranberry extracts or juices was done using a microtechnique based on the non-enzymatic peroxidation of rat liver microsomes method modified [19] where artificial membranes were used instead of rat liver microsomes, in order to obtain a more stable and reproducible system. This test measures by spectrophotometry the TBARS (thiobarbituric reactive substances) concentration producted during the peroxidation of liposomes exposed to iron ions in $20 \mathrm{mM}$ phosphate buffer solution in presence of ascorbate. The antioxidant activity is equivalent to the lipid peroxidation inhibition capacity.

Liposomes preparation: Liposomes were formed by an injection method, as described by Batzri and Korn [20]. Linoleic acid (Sigma-Aldrich, Oakville, ON, Canada) was dissolved in $95 \%$ ethanol. The mixture was injected into phosphate buffer $(20 \mathrm{mM}, \mathrm{pH} 7.4)$ in a proportion of 1:9 $(\mathrm{v} / \mathrm{v})$, using an hypodermic syringe fitted with a fine needle (G26).

Microplate preparation: Twenty five $\mu$ of samples and controls were added to a microplate (96 wells). Three final concentrations for each fraction $(19.5,78.2,313 \mu \mathrm{g} / \mathrm{ml})$ were tested [19]. The reaction mixture containing $4 \mathrm{~mL}$ of liposomes solution, $2.25 \mathrm{~mL}$ of phosphate buffer (20 $\mathrm{mM}, \mathrm{pH} 7.4)$ and $0.25 \mathrm{~mL}$ of ascorbate solution (3.1 $\mathrm{mg} / \mathrm{mL}$ ) was prepared. Sixty five $\mu \mathrm{L}$ of reaction mixture was added to a microplate using a multichannel pipette. Finally, $10 \mu \mathrm{L}$ of $\mathrm{FeCl}$ (Sigma-Aldrich) solution $(4.3 \mathrm{mg} /$ $\mathrm{mL}$ ) were added to the wells. The microplate was then incubated at $37^{\circ} \mathrm{C}$ for 15 minutes. One hundred fifty $\mu \mathrm{L}$ of a fresh solution of $10 \%(\mathrm{v} / \mathrm{v})$ SDS (Sigma-Aldrich) and $0.67 \%(\mathrm{v} / \mathrm{v})$ thiobarbituric acid (Sigma-Aldrich) in a 1:2 ratio was added in the microplate. The colorimetric reaction was produced at $80^{\circ} \mathrm{C}$ for $30 \mathrm{~min}$. The TBARS of the controls and samples were evaluated at $540 \mathrm{~nm}$ with a Microplate Autoreader (model EL 309, Biotek Instruments, Winooski, VT). The positive control was represented by the reaction mixture in presence of Trolox without the sample, and the optical density of the chromogen formed denoted complete peroxidation. The negative control contained only the phosphate buffer without liposomes. The relative antioxidant activity was calculated using the following equation:

$$
\begin{aligned}
\mathrm{AA}(\%)= & {\left[\mathrm{OD}_{(\text {negative control) }}-\mathrm{OD}_{(\text {sample) }} / \mathrm{OD}_{(\text {(negative control) }}\right.} \\
& \left.-\mathrm{OD}_{(\text {positive control) }}\right] \times 100
\end{aligned}
$$

Thus extracts or juice able to inhibit completely the lipid peroxidation will have a $100 \%$ antioxidant capacity. Then, data were reported to the quantity of dry matter of each sample and the quantity of phenolic compounds and results were expressed as Trolox ${ }^{\circledR}$ equivalent (TE)/mg of dry matter or Trolox ${ }^{\circledR}$ equivalent/mg of phenol relatively to the positive control.

\subsection{Statistical Analysis of Data}

Analysis of variance and Duncan's multiple-range was done using Stat-Packets Statistical Analysis software (Walonick Associates Inc., MN, USA) for the determination of antiradical and antioxidant activities. Differences between means were considered significant when $p \leq$ 0.05 . These experiments were repeated three times.

\section{Results and Discussion}

\subsection{Antiradical Activity}

HPLC analysis (Figure 1) allowed according to their polarity the separation of the phenolic compounds obtained from two cranberry juices and three extracts isolated from frozen cranberries and pomace containing anthocyanins, water-soluble and apolar phenolic compounds. The most polar phenolic compounds presented the shortest elution times and low molecular weight (MW). Between three and four fractions from each juice or extract were collected according to conditions defined in Table 1, in order to collect compounds with close polarities The phenolic content of fractions might be evaluated through standard phenolic compounds and their retention time: phenolic acids (gallic acid: $6.27 \mathrm{~min}$, chlorogenic acid: 7.14 min, caffeic acid: $10.41 \mathrm{~min}, p$-coumaric acid: 17.25 $\mathrm{min}$ ), anthocyanins (cyanidin 3-galactoside: $19.04 \mathrm{~min}$, cyanidin 3-arabinoside: $22.96 \mathrm{~min}$, peonidin 3-galactoside: $24.22 \mathrm{~min}$, peonidin 3-arabinoside: $26.12 \mathrm{~min}$ ), flavonols (myricetin 3-galactoside: $29.12 \mathrm{~min}$, quercetin 3galactoside: $31.79 \mathrm{~min}$, myricetin 3-arabinoside: 32.14 min, quercetin 3-arabinoside: $34.48 \mathrm{~min}$ ) and proanthocyanidins (with DP of 5: $48.19 \mathrm{~min}$, with DP of 6: 56.33 min). Thus in fractionation into 4 fractions, Fraction 1 was enriched in phenolic acids, Fraction 2 was enriched in anthocyanins, Fraction 3 was enriched in flavonols and Fraction 4 was enriched in proanthocyanidins. In fractionation into 3 fractions, Fraction 1 was enriched in phenolic acids, Fraction 2 was enriched in anthocyanins and flavonols, Fraction 3 was enriched in flavonols and proanthocyanidins.

The free radical-scavenging capacity of these fractions is presented in Table 2. When data were reported to the quantity of dry matter of each sample, the results showed that the fraction 2 (enriched in anthocyanins and flavonols) of extract rich in apolar phenolic compounds (E2) of fruit presented the highest free radical-scavenging activities ( $39.58 \mathrm{mM} \mathrm{TE} / \mathrm{mg}$ dry matter) followed by the fraction 2 (enriched in anthocyanins) of clarified juice (7 mM TE/ $\mathrm{mg}$ dry matter). Conversely, fractions 1 (enriched in phenolic acids) and 4 (enriched in proanthocyanidins) of extract rich in water-soluble phenolic compounds (E1) obtained from fruit, fraction 1 (enriched in phenolic acids) 
Table 2. Radical-scavenging capacity of each fraction from cranberry juices and three extracts of cranberry fruits and pomace.

\begin{tabular}{|c|c|c|c|}
\hline \multirow[t]{2}{*}{ Samples $^{\mathrm{a}}$} & \multirow[t]{2}{*}{ Fractions } & \multicolumn{2}{|c|}{ Free radical scavenging capacity ${ }^{b, c, d}$} \\
\hline & & $\begin{array}{l}\mathrm{mM} \mathrm{TE} / \mathrm{mg} \\
\text { fraction }\end{array}$ & $\begin{array}{c}\mathrm{mM} \mathrm{TE} / \mathrm{mg} \\
\text { phenol }\end{array}$ \\
\hline \multirow{4}{*}{ Fruit E1 } & 1 & $0.43 \pm 0.05 \mathrm{~h}$ & $43.42 \pm 4.70 \mathrm{t}$ \\
\hline & 2 & $3.94 \pm 0.13 \mathrm{~m}$ & $30.82 \pm 2.41 \mathrm{qr}$ \\
\hline & 3 & $4.02 \pm 0.12 \mathrm{~m}$ & $14.21 \pm 0.92 \mathrm{~m}$ \\
\hline & 4 & $0.38 \pm 0.03 \mathrm{gh}$ & $19.80 \pm 1.660$ \\
\hline \multirow{3}{*}{ Fruit E2 } & 1 & $0.74 \pm 0.05 i$ & $7.40 \pm 0.51 \mathrm{j}$ \\
\hline & 2 & $39.58 \pm 3.160$ & $40.39 \pm 4.07 \mathrm{st}$ \\
\hline & 3 & $2.02 \pm 0.34 j$ & $111.61 \pm 12.81 \mathrm{v}$ \\
\hline \multirow{4}{*}{ Fruit E3 } & 1 & $-1.52 \pm 0.10 \mathrm{a}$ & $-38.48 \pm 2.99 \mathrm{a}$ \\
\hline & 2 & $3.85 \pm 0.12 \mathrm{~m}$ & $49.29 \pm 5.21 \mathrm{t}$ \\
\hline & 3 & $4.04 \pm 0.44 \mathrm{~m}$ & $33.45 \pm 3.01 \mathrm{rs}$ \\
\hline & 4 & $3.91 \pm 0.15 \mathrm{~m}$ & $15.37 \pm 1.67 \mathrm{mn}$ \\
\hline \multirow{4}{*}{ Pomace E1 } & 1 & $0.01 \pm 0.001 \mathrm{e}$ & $0.12 \pm 0.01 \mathrm{f}$ \\
\hline & 2 & $0.33 \pm 0.03 \mathrm{fg}$ & $1.14 \pm 0.12 \mathrm{~g}$ \\
\hline & 3 & $0.38 \pm 0.03 \mathrm{gh}$ & $2.79 \pm 0.34 \mathrm{~h}$ \\
\hline & 4 & $0.30 \pm 0.03 \mathrm{f}$ & $25.00 \pm 1.66 \mathrm{p}$ \\
\hline \multirow{4}{*}{ Pomace E2 } & 1 & $2.95 \pm 0.19 \mathrm{k}$ & $25.21 \pm 2.08 \mathrm{p}$ \\
\hline & 2 & $2.79 \pm 0.21 \mathrm{jkl}$ & $25.36 \pm 2.11 \mathrm{~m}$ \\
\hline & 3 & $2.99 \pm 0.30 \mathrm{k}$ & $11.50 \pm 1.021$ \\
\hline & 4 & $3.08 \pm 0.31 \mathrm{k}$ & $18.01 \pm 2.04 \mathrm{no}$ \\
\hline \multirow{3}{*}{ Pomace E3 } & 1 & $2.87 \pm 0.25 \mathrm{k}$ & $26.09 \pm 2.49 p$ \\
\hline & 2 & $3.28 \pm 0.31 \mathrm{kl}$ & $10.93 \pm 1.05 \mathrm{kl}$ \\
\hline & 3 & $3.25 \pm 0.30 \mathrm{kl}$ & $9.02 \pm 0.89 \mathrm{k}$ \\
\hline \multirow{4}{*}{ Clarified juice } & 1 & $-0.49 \pm 0.31 b$ & $-3.06 \pm 2.15 b$ \\
\hline & 2 & $7.36 \pm 0.40 \mathrm{n}$ & $56.61 \pm 4.08 \mathrm{u}$ \\
\hline & 3 & $3.84 \pm 0.341 \mathrm{~m}$ & $3.84 \pm 0.38 \mathrm{i}$ \\
\hline & 4 & $2.82 \pm 0.27 \mathrm{k}$ & $25.63 \pm 2.19 p$ \\
\hline \multirow{4}{*}{ Juice concentrate } & 1 & $0.0026 \pm 0.0005 \mathrm{~d}$ & $0.075 \pm 0.007 \mathrm{e}$ \\
\hline & 2 & $0.0103 \pm 0.0014 \mathrm{e}$ & $0.026 \pm 0.004 \mathrm{~d}$ \\
\hline & 3 & $0.0017 \pm 0.0007 \mathrm{~cd}$ & $0.017 \pm 0.002 \mathrm{c}$ \\
\hline & 4 & $0.0011 \pm 0.0003 c$ & $0.068 \pm 0.005 \mathrm{e}$ \\
\hline
\end{tabular}

${ }^{\mathrm{a}} \mathrm{E} 1, \mathrm{E} 2$ and E3 are three extracts from cranberry fruits. E1: the most watersoluble phenolic compounds extracted with water/methanol $(85 / 15$. v/v); E2: the most apolar phenolic compounds extracted with acetone/methanol/ water (40/40/20. v/v); E3: anthocyanins extracted with methanol/water/acetic acid $(85 / 14.5 / 0.5 . \mathrm{v} / \mathrm{v} / \mathrm{v}) .{ }^{\mathrm{b}} \mathrm{TE}$ : Trolox ${ }^{\circledR}$ equivalent. ${ }^{\mathrm{c}}$ Values are means \pm standard deviations. Within each column, means bearing the same lowercase letter are not significantly different $(P>0.05) .{ }^{\mathrm{d}} \mathrm{A}$ negative result indicates that the fraction is pro-oxidant. of fruit E2, all fractions of pomace E1 showed a low free radical-scavenging capacity. Moreover, all fractions of concentrate showed a very low free radical-scavenging capacity (between 0.001 and $0.01 \mathrm{mM} \mathrm{TE} / \mathrm{mg}$ dry matter). It appears that conditions of the evaporation to obtain a juice concentrate exerted a significant effect $(P \leq$ $0.05)$ on bioactive molecule content and their antiradical properties. Also, two fractions (i.e. fractions 1 enriched in phenolic acids from clarified juice and anthocyanin-rich cranberry extract (E3) of fruit) were shown slightly prooxidant. The other fractions showed an average free radical-scavenging capacity (between 2 and $4 \mathrm{mM} \mathrm{TE} / \mathrm{mg}$ dry matter).

Among the samples, phenolic compounds of fraction 3 (enriched in flavonols and proanthocyanidins) of fruit E2 showed the highest free radical-scavenging activity (111 $\mathrm{mM} \mathrm{TE} / \mathrm{mg}$ phenol) when results were expressed in $\mathrm{mM}$ Trolox ${ }^{\circledR}$ equivalent/mg phenol. The extraction conditions of the extract rich in water-soluble phenolic compounds (E1) (water/methanol $(85: 15, \mathrm{v} / \mathrm{v}))$ were similar to those employed for juice (water). All fractions of fruit E1 showed an important free radical-scavenging activity (between 14 and $43 \mathrm{mM} \mathrm{TE} / \mathrm{mg}$ phenol) while antiradical activity of phenol compounds in all fractions of juice concentrate was extremely low (below $0.75 \mathrm{mM} \mathrm{TE} / \mathrm{mg}$ phenol). Thus, the data obtained reveal that the technological process to manufacture cranberry juice has influenced the phenolic compound content Also, the free radical-scavenging capacity of phenolic compounds was reduced in fractions 1 (enriched in phenolic acids) and 3 (enriched in flavonols) from clarified juice and fractions 1 to 3 from presscake E1 compared to that obtained with the corresponding fractions of fruit E1. It tends to prove that extraction has led to the recovery of most bioactive molecules, except for molecules of the less polar fraction (enriched in proanthocyanidins) of pomace E1. Moreover, it is also important to note that most fractions of E2 and E3 contained phenolic compounds with good or very good free radical-scavenging activities, except for fraction 1 (enriched in phenolic acids) of fruit E3 which phenolic compounds were pro-oxidant.

\subsection{Antioxidant Activity}

The capacity of lipid peroxidation inhibition of each fraction at three concentrations $(19.5,78.1$ and $313 \mu \mathrm{g} /$ $\mathrm{mL}$ ) is presented in Table 3. The results showed that the antioxidant or pro-oxidant activity of fractions increased with the concentration. Of all the samples tested, the most hydrophobic fractions (enriched in proanthocyanidins) of the anthocyanin-rich cranberry extract (E3) from fruit and pomace appeared to be the most efficient at inhibiting the lipid peroxidation (above $2 \mathrm{TE} / \mathrm{mg}$ dry matter) when results were expressed in Trolox ${ }^{\circledR}$ equivalent/mg 
Table 3. Lipid peroxidation inhibition capacity of each fraction from cranberry juices and three extracts of cranberry fruits and pomace.

\begin{tabular}{|c|c|c|c|c|c|c|c|}
\hline \multirow{3}{*}{ Samples ${ }^{\mathrm{a}}$} & \multirow{3}{*}{ Fractions } & \multicolumn{6}{|c|}{ Lipid peroxidation inhibition capacity ${ }^{b, c, d}$} \\
\hline & & \multicolumn{3}{|c|}{$\mathrm{TE} / \mathrm{mg}$ fraction } & \multicolumn{3}{|c|}{$\mathrm{TE} / \mathrm{mg}$ phenol } \\
\hline & & $19.5 \mu \mathrm{g} / \mathrm{ml}$ & $78.2 \mu \mathrm{g} / \mathrm{ml}$ & $313 \mu \mathrm{g} / \mathrm{ml}$ & $19.5 \mu \mathrm{g} / \mathrm{ml}$ & $78.2 \mu \mathrm{g} / \mathrm{ml}$ & $313 \mu \mathrm{g} / \mathrm{ml}$ \\
\hline \multirow{3}{*}{ Fruit E1 } & 1 & $-0.03 \pm 0.01 \mathrm{Bc}$ & $-0.02 \pm 0.01 \mathrm{Bd}$ & $-0.19 \pm 0.01 \mathrm{Ac}$ & $-2.39 \pm 0.24 \mathrm{Ba}$ & $-1.84 \pm 0.19 \mathrm{Cd}$ & $-19.01 \pm 1.29 \mathrm{Ab}$ \\
\hline & 3 & $0.56 \pm 0.07 \mathrm{Ak}$ & $1.35 \pm 0.29 \mathrm{Bo}$ & $1.54 \pm 0.15 \mathrm{Bn}$ & $1.99 \pm 0.23 \mathrm{Aj}$ & $4.80 \pm 0.28 \mathrm{~Bq}$ & $5.42 \pm 0.37 \mathrm{Bo}$ \\
\hline & 4 & $0.37 \pm 0.03 \mathrm{Aij}$ & $0.46 \pm 0.04 \mathrm{Bjk}$ & $0.76 \pm 0.06 \mathrm{Ckl}$ & $19.79 \pm 1.40 \mathrm{Ao}$ & $24.01 \pm 2.22 \mathrm{Btu}$ & $39.89 \pm 2.85 \mathrm{Cu}$ \\
\hline \multirow[b]{2}{*}{ Fruit E2 } & 1 & $0.02 \pm 0.01 \mathrm{Cd}$ & $-0.008 \pm 0.001 \mathrm{Be}$ & $-0.11 \pm 0.01 \mathrm{Ae}$ & $0.25 \pm 0.02 \mathrm{Be}$ & $-0.08 \pm 0.01 \mathrm{Af}$ & $-1.10 \pm 0.04 \mathrm{Ag}$ \\
\hline & 2 & $0.18 \pm 0.01 \mathrm{Ag}$ & $0.43 \pm 0.03 \mathrm{Bj}$ & $0.92 \pm 0.05 \mathrm{Cm}$ & $0.19 \pm 0.01 \mathrm{Ad}$ & $0.44 \pm 0.02 \mathrm{Bi}$ & $0.61 \pm 0.03 \mathrm{Ci}$ \\
\hline \multirow{4}{*}{ Fruit E3 } & 1 & $0.03 \pm 0.01 \mathrm{Ade}$ & $0.26 \pm 0.09 \mathrm{Bhi}$ & $0.33 \pm 0.02 \mathrm{Bh}$ & $3.12 \pm 0.36 \mathrm{Akl}$ & $22.47 \pm 2.12 \mathrm{Bt}$ & $27.85 \pm 2.71 \mathrm{Ct}$ \\
\hline & 2 & $1.13 \pm 0.11 \mathrm{Amn}$ & $1.56 \pm 0.15 \mathrm{Bo}$ & $1.48 \pm 0.23 \mathrm{Bn}$ & $9.38 \pm 0.56 \mathrm{An}$ & $12.95 \pm 1.88 \mathrm{Bs}$ & $12.29 \pm 1.90 \mathrm{Bs}$ \\
\hline & 3 & $0.04 \pm 0.01 \mathrm{Ae}$ & $0.11 \pm 0.02 \mathrm{Bg}$ & $0.81 \pm 0.06 \mathrm{Clm}$ & $0.34 \pm 0.03 \mathrm{Af}$ & $0.97 \pm 0.14 \mathrm{Bk}$ & $6.72 \pm 0.61 \mathrm{Cpq}$ \\
\hline & 4 & $1.49 \pm 0.31 \mathrm{An}$ & $2.10 \pm 0.21 \mathrm{Bp}$ & $2.30 \pm 0.29 \mathrm{Bo}$ & $19.07 \pm 1.93 \mathrm{Ao}$ & $27.01 \pm 2.08 \mathrm{Bu}$ & $29.46 \pm 2.87 \mathrm{Bt}$ \\
\hline \multirow{4}{*}{ Pomace E1 } & 1 & $-0.09 \pm 0.01 \mathrm{Ab}$ & $-0.09 \pm 0.01 \mathrm{Ac}$ & $-0.15 \pm 0.01 \mathrm{Ad}$ & $-1.11 \pm 0.10 \mathrm{Bb}$ & $-1.12 \pm 0.11 \mathrm{Be}$ & $-1.87 \pm 0.16 \mathrm{Ae}$ \\
\hline & 2 & $0.37 \pm 0.03 \mathrm{Aij}$ & $0.53 \pm 0.05 \mathrm{Bkl}$ & $0.64 \pm 0.06 \mathrm{Bjk}$ & $1.28 \pm 0.11 \mathrm{Ahi}$ & $1.85 \pm 0.07 \mathrm{Bm}$ & $2.22 \pm 0.25 \mathrm{Cl}$ \\
\hline & 3 & $0.20 \pm 0.03 \mathrm{Ag}$ & $0.84 \pm 0.08 \mathrm{Bn}$ & $1.72 \pm 0.16 \mathrm{Cn}$ & $1.47 \pm 0.13 \mathrm{Ai}$ & $6.20 \pm 0.57 \mathrm{Br}$ & $12.65 \pm 1.23 \mathrm{Cs}$ \\
\hline & 4 & $0.31 \pm 0.03 \mathrm{Ahi}$ & $0.57 \pm 0.04 \mathrm{Blm}$ & $0.76 \pm 0.06 \mathrm{Ckl}$ & $26.41 \pm 2.32 \mathrm{Ap}$ & $48.26 \pm 3.27 \mathrm{Bv}$ & $63.50 \pm 4.36 \mathrm{Cv}$ \\
\hline \multirow{3}{*}{ Pomace E2 } & 2 & $0.29 \pm 0.02 \mathrm{Ah}$ & $0.60 \pm 0.05 \mathrm{Blm}$ & $0.86 \pm 0.07 \mathrm{Clm}$ & $1.15 \pm 0.10 \mathrm{Ah}$ & $2.37 \pm 0.21 \mathrm{Bno}$ & $3.43 \pm 0.43 \mathrm{Cmn}$ \\
\hline & 3 & $0.02 \pm 0.01 \mathrm{Ad}$ & $0.20 \pm 0.02 \mathrm{Bh}$ & $0.31 \pm 0.03 \mathrm{Ch}$ & $0.10 \pm 0.01 \mathrm{Ac}$ & $0.79 \pm 0.06 \mathrm{Bjk}$ & $1.22 \pm 0.21 \mathrm{Cj}$ \\
\hline & 4 & $0.70 \pm 0.06 \mathrm{Bl}$ & $-1.27 \pm 0.12 \mathrm{Aa}$ & $-1.30 \pm 0.14 \mathrm{Aa}$ & $2.75 \pm 0.26 \mathrm{Bk}$ & $-4.99 \pm 0.43 \mathrm{Ab}$ & $-5.12 \pm 0.52 \mathrm{Ac}$ \\
\hline \multirow{3}{*}{ Pomace E3 } & 1 & $0.15 \pm 0.02 \mathrm{Ag}$ & $0.44 \pm 0.03 \mathrm{Bj}$ & $0.61 \pm 0.06 \mathrm{Cj}$ & $1.42 \pm 0.13 \mathrm{Ai}$ & $4.02 \pm 0.39 \mathrm{Bp}$ & $5.59 \pm 0.42 \mathrm{Co}$ \\
\hline & 2 & $1.10 \pm 0.09 \mathrm{Amn}$ & $1.43 \pm 0.13 \mathrm{Bo}$ & $1.79 \pm 0.15 \mathrm{Cn}$ & $3.68 \pm 0.34 \mathrm{Al}$ & $4.78 \pm 0.44 \mathrm{Bpq}$ & $5.98 \pm 0.51 \mathrm{Cop}$ \\
\hline & 3 & $1.26 \pm 0.11 \mathrm{An}$ & $2.17 \pm 0.18 \mathrm{Bp}$ & $2.52 \pm 0.24 \mathrm{Bo}$ & $3.50 \pm 0.33 \mathrm{Al}$ & $6.05 \pm 0.58 \mathrm{Br}$ & $7.01 \pm 0.21 \mathrm{Cq}$ \\
\hline \multirow{4}{*}{ Clarified juice } & 1 & $-0.47 \pm 0.03 \mathrm{Ab}$ & $-0.48 \pm 0.03 \mathrm{Ab}$ & $-0.49 \pm 0.03 \mathrm{Ab}$ & $-2.94 \pm 0.31 \mathrm{Aa}$ & $-3.01 \pm 0.30 \mathrm{Ac}$ & $-3.10 \pm 0.35 \mathrm{Ad}$ \\
\hline & 2 & $0.19 \pm 0.02 \mathrm{Ag}$ & $0.26 \pm 0.04 \mathrm{Bhi}$ & $0.36 \pm 0.03 \mathrm{Ch}$ & $1.45 \pm 0.13 \mathrm{Ai}$ & $1.99 \pm 0.14 \mathrm{Bmn}$ & $2.82 \pm 0.24 \mathrm{Cm}$ \\
\hline & 3 & $0.44 \pm 0.04 \mathrm{Aj}$ & $0.65 \pm 0.04 \mathrm{Bm}$ & $0.93 \pm 0.06 \mathrm{Cm}$ & $0.45 \pm 0.04 \mathrm{Ag}$ & $0.66 \pm 0.06 \mathrm{Bj}$ & $0.95 \pm 0.09 \mathrm{Cj}$ \\
\hline & 4 & $0.42 \pm 0.04 \mathrm{Aj}$ & $0.58 \pm 0.05 \mathrm{Blm}$ & $0.88 \pm 0.07 \mathrm{Clm}$ & $3.82 \pm 0.34 \mathrm{Al}$ & $5.36 \pm 0.51 \mathrm{Bqr}$ & $8.01 \pm 0.75 \mathrm{Cr}$ \\
\hline \multirow{4}{*}{ Juice concentrate } & 1 & $0.16 \pm 0.02 \mathrm{Ag}$ & $0.20 \pm 0.02 \mathrm{Ah}$ & $0.25 \pm 0.02 \mathrm{Bg}$ & $1.83 \pm 0.14 \mathrm{Aj}$ & $2.24 \pm 0.17 \mathrm{Bn}$ & $2.35 \pm 0.21 \mathrm{Bl}$ \\
\hline & 2 & $1.10 \pm 0.11 \mathrm{Amn}$ & $1.45 \pm 0.12 \mathrm{Bo}$ & $1.70 \pm 0.15 \mathrm{Bn}$ & $1.13 \pm 0.13 \mathrm{Ah}$ & $1.48 \pm 0.12 \mathrm{Bl}$ & $1.74 \pm 0.16 \mathrm{Bk}$ \\
\hline & 3 & $0.50 \pm 0.01 \mathrm{Ak}$ & $0.48 \pm 0.02 \mathrm{Ajk}$ & $0.51 \pm 0.01 \mathrm{Ai}$ & $0.12 \pm 0.02 \mathrm{Ac}$ & $0.10 \pm 0.01 \mathrm{Ah}$ & $0.12 \pm 0.02 \mathrm{Ah}$ \\
\hline & 4 & $0.09 \pm 0.01 \mathrm{Af}$ & $0.09 \pm 0.01 \mathrm{Ag}$ & $0.10 \pm 0.01 \mathrm{Af}$ & $6.01 \pm 0.53 \mathrm{Am}$ & $5.98 \pm 0.44 \mathrm{Ar}$ & $6.21 \pm 0.57$ Aop \\
\hline
\end{tabular}

${ }^{a} \mathrm{E} 1, \mathrm{E} 2$ and E3 are three extracts from cranberry fruits. E1: the most water-soluble phenolic compounds extracted with water/methanol (85/15. v/v); E2: the most apolar phenolic compounds extracted with acetone/methanol/water (40/40/20. v/v); E3: anthocyanins extracted with methanol/water/acetic acid $(85 / 14.5 / 0.5 . \mathrm{v} / \mathrm{v} / \mathrm{v}) .{ }^{\mathrm{b}} \mathrm{TE}$ : Trolox ${ }^{\circledR}$ equivalent. ${ }^{\mathrm{c}}$ Values are means \pm standard deviations. Means in the same row bearing the same uppercase letter are not significantly different $(P>0.05)$. Means in each column bearing the same lowercase letter are not significantly different $(P>0.05)$. ${ }^{\mathrm{A}} \mathrm{A}$ negative result indicates that the fraction is pro-oxidant. 
dry matter. However, most of the fractions showed a weak antioxidant activity (below $1 \mathrm{TE} /$ dry matter). Also, fractions 1 (enriched in phenolic acids) of E1, E2 and clarified juice and fraction 4 (enriched in proanthocyanidins) of E2 were slightly pro-oxidant.

Among the samples, the phenolic compounds present in the more hydrophobic fractions (enriched in proanthocyanidins) from fruit and pomace E1 showed the highest antioxydant activity (63 and $39 \mathrm{TE} / \mathrm{mg}$ phenol, respectively) when results were expressed in Trolox ${ }^{\circledR}$ equivalent/mg phenol. Antioxidant activities of phenolic fractions of E1 and juices increased as their polarities decreased. Also, it is interesting to note that phenols present in the most hydrophobic fraction (enriched in flavonols and proanthocyanidins) of fruit E2 at $19.5 \mu \mathrm{g} / \mathrm{ml}$ showed a very good capacity of lipid peroxidation inhibition (51 $\mathrm{TE} / \mathrm{mg}$ phenol) while they were strongly pro-oxidant at $313 \mu \mathrm{g} / \mathrm{ml}$ ( $-28 \mathrm{TE} / \mathrm{mg}$ phenol). Moreover, the phenols of E3 fractions showed a good antioxidant activity while the phenolic compounds present in fraction 1 (enriched in phenolic acids) of E1 and in many fractions of E2 and two juices showed a low capacity of lipid peroxidation inhibition or pro-oxidant properties.

The data obtained reveal that many fractions of cranberry extracts and juices are free radical-scavengers and primary antioxidants, which react with free radicals and inhibit the lipid peroxidation. However, the phenolic compounds of most fractions of cranberry extracts and juices contributed substantially to the radical scavenging activity, while the lipid peroxidation inhibition activity was attributable to the most hydrophobic fractions composed mainly of large polyphenols (i.e. proanthocyanidins and flavonoid oligomers) and this in spite of the low total amounts of these compounds present. Also, the more polar fraction of cranberry extracts and juices, containing mainly phenolics acids, organic acids and sugars, promoted generally lipid oxidation. Numerous classes of phenolic compounds are present in cranberry juice and by-products of cranberry-juice processing (e.g., press cake) [21,22]. The wide range of phenolics in cranberry known to contribute to the characteristic antioxidant activity profile include the catechins, quercetin, p-coumaric acid, chlorogenic acid, myricetin, trans-resveratrol and cyanidin/peonidin 3-galactoside/arabinoside [23-25], The concentration of these compounds in cranberry will vary depending on the maturity and variety of the cranberry fruit [26]. Moreover, the extent to which particular phenolic compounds contribute to the total antioxidant capacity of cranberry may also depend on both the relative concentration of individual antioxidant compounds, as well as possible synergistic interactions between different fruit constituents [25].

The antioxidant and antiradical activities of phenol fractions from aqueous extract (E1) of cranberry differ from those of phenol fractions from solvent extracts (E2 or E3). Antioxidant activities of phenol fractions of E1 increased as their polarities decreased, but this is not the case with phenol fractions from solvent extracts. Also, antiradical activities of phenol fractions from fruit E1 decreased as their polarities decreased, whereas those of phenol fractions from fruit E2 increased as their polarities decreased. The reason is certainly the variation of solubility of compounds extracted in water or solvents, which is connected to their hydrophilic or hydrophobic character. In the present study, it appears that the polarity of phenolic compounds is a determinant of antioxidant and antiradical activities. Thus, antioxidant activity will differ depending on the phenolic molecular structure [9], and antiradical activity is dependent on the structure of the free radical-scavenging compounds and the substituents present on the ring of the flavonoids [27]. The polarity of the flavonoids depends primarily on the nature of the radicals on rings, and in particular on the number of $\mathrm{OH}$ groups [2]. Thus, the spatial arrangement of substituents is a greater determinant of antiradical and antioxidant activities than the flavan backbone alone [28]. The differences in antioxidant activity between polyhydroxylated and polymethoxylated flavonoids are most likely due to differences in both hydrophobicity and molecular planarity [2]. Consistent with most polyphenolic antioxidants, both the configuration and total number of hydroxyl groups substantially influence several mechanisms of antiradical activity [28]. Our results indicate that the phenols of polar fractions (1 and 2) from fruit E1 have free radical-scavenging capacities which are more significant than those of phenols of less polar fractions ( 3 and 4). Free radical-scavenging capacity is primarily attributed to the high reactivities of hydroxyl substituents. Hydroxyl groups on the B-ring donate hydrogen and an electron to hydroxyl, peroxyl, and peroxynitrite radicals, stabilizing them and giving rise to a relatively stable flavonoid radical. Among structurally homologous flavones and flavanones, peroxyl- and hydroxyl-scavenging increases linearly and curvilinearly, respectively, according to the total number of $\mathrm{OH}$ groups [29]. The glycosylated derivatives also have an influence on the polarity of the molecule. In general, the glycosylated compounds have a weaker antiradical activity than their aglycone equivalent [30]. The key role of flavonoids, as scavengers of free radicals, is emphasized in several reports [31]. Flavonoids with adjacent dihydroxy substituents on the B ring have been shown to be effective in radical scavenging [24]. This was the case, in particular, for catechol unit found in quercetin of flavonols, cyanidin of anthocanidins, catechins of flavan-3-ols, and procyanidins of poanthocyanidins. In cranberry, anthocyanins are among the principal antioxidant constituents, although hydroxycinnamates such as chlorogenic acid, hydrolyzable tannins and con- 
densed tannins are also effective antioxidants. The contribution of other flavonoids, such as flavonols, to the antioxidant effect of cranberry is generally much less significant compared to the activity of anthocyanins and tannins [8]. The condensed tannins (proanthocyanidins) in cranberry were shown to be effective antioxidants in various food environments such as bulk oil, emulsions, liposomes, as well as toward oxidation of LDL [8].

Our results indicate that the cranberry phenols of fractions are good free radical-scavengers, but several cranberry phenol fractions were less efficient at inhibiting the lipid peroxidation. The method used to evaluate the lipid peroxidation inhibition activity of phenols is based on the Fenton reaction and detects non-enzymatic autoxidation [19]. The oligomeric proanthocyanidins have been noted for their ability to inhibit low molecular weight iron-mediated lipid oxidation compared to their monomeric counterparts $[10,32]$ and the number of catechol units in the reaction mixture was found to positively correlate with the ability of catechins and procyanidins to protect against lipid oxidation [33]. Among cranberry phenol fractions of different polarity, Lee et al. [11] showed that the most apolar fraction was the most effective fraction in inhibiting thiobarbituric acid reactive substances (TBARS) formation. This could explain the high capacity of lipid peroxidation inhibition observed in fraction 4 from fruit and pomace E1. The smaller flavonol aglycones such as quercetin on the other hand have been shown to orient readily into membrane bilayers [34]. Interestingly, quercetin, which is a major phenolic phytochemical present in cranberries, can completely suppress Fe-promoted Fenton chemistry at micromolar levels even in the presence of the major cellular iron chelators ATP or citrate [35]. However, the radical scavenging activity of quercetin provides only partial protection against Fenton chemistry-mediated damage while Fe chelation by quercetin can completely inhibit Fenton chemistry, indicating that the chelation may be key to its antioxidant activity [36]. Also, several reports indicate that some phenolic acids exert apparently conflicting effects on the Fenton reaction depending on the oxidation conditions and that they are potential prooxidants [37]. Thus, benzoic acid, caffeic acid and chlorogenic acid can enhanced lipid oxidation and exhibited prooxidant and antioxidant activities depending on the lipid oxidation phases (incubation time) and their concentration [38]. This could explain the prooxidant activities observed in fractions 1 from fruit E1 and E2, pomace E1 and juices.

The technological process to manufacture cranberry juice can also influence the antioxidant and antiradical activities, since fractions from clarified juice, juice concentrate and pomace showed activities much lower than those observed with corresponding fractions from cranberry fruit extracts, in particularly with fractions from E1 which the extraction conditions were similar to those used to obtain the juice. Apart from the genetic characters of raw materials, also the conditions of the technological process exert a significant effect on the concentrations of antioxidants and the free radical-scavenging compounds in juices and on their final properties [39]. The release of antioxidants and free radical-scavenging compounds into the juice is considerably affected by the parameters of unit operations during processing, such as fruit crushing and mash heating, as well as by the type of enzymatic preparation used for mash maceration, and juice pressing conditions [40].

\section{Conclusion}

Our results showed that the phenolic compounds present in cranberry fractions have antioxidant and antiradical activities, and suggest that even a partial purification of these compounds has an important impact on their antioxidant and free radical scavenging activities. Antiradical and antioxidant activities of fractions reflect the structure-activity relationship, it appears that the polarity of phenolic compounds is a determinant of these activities. The present work indicated that the cranberry phenols are good free radical-scavengers, but they were less efficient at inhibiting the lipid peroxidation. The antioxidant effect was dose dependent at the concentration levels used, in general, fractions were good antioxidant only at the higher concentration of $313 \mu \mathrm{g} / \mathrm{mL}$. Also, the technological process to manufacture cranberry juice has negatively affected the antioxidant and antiradical activities of all fractions regardless of polarity. However, phenols present in most fractions of fruit extracts have shown very interesting antiradical properties while phenols in the most hydrobobic fractions of extract rich in water-soluble phenolic compounds and the anthocyanin-rich cranberry extract had a remarkable action against lipid oxidation. These fractions represent antioxidant sources that may have potential for inducing beneficial effects on human health, and in general, our results showed that the cranberry fractions contain significant amounts of antioxidant active compounds, which may be regarded as a promising natural additive for health beneficial functional foods and nutraceuticals.

\section{Acknowledgements}

This research was supported by the Natural Sciences and Engineering Research Council of Canada (NSERC) and by Atoka Cranberries Inc. (Manseau, QC, Canada).

\section{REFERENCES}

[1] O. I. Aruoma, "Free Radicals, Oxidative Stress, and Antioxidants in Human Health and Disease," Journal of the 
American Oil Chemists Society, Vol. 75, No. 2, 1998, pp. 199-212. doi:10.1007/s11746-998-0032-9

[2] K. E. Heim, A. R. Tagliaferro and D. J. Bobilya, "Flavonoid Antioxidants: Chemistry, Metabolism and Structure-Activity Relationships," The Journal of Nutritional Biochemistry, Vol. 13, No. 10, 2002, pp. 572-584. doi:10.1016/S0955-2863(02)00208-5

[3] J. J. Macheix, A. Fleuriet and J. Billot, "Fruit Phenolics," CRC Press, Boca Raton, 1990.

[4] J. A. Mantley and B. S. Buslig, "Flavonoids in the Living System," In: J. A. Mantley and B. S. Buslig, Eds., Advances in Experimental Medicine and Biology, Plenum Press, New York, 1998, p. 278.

[5] I. M. Heinonen, A. S. Meyer and E. N. Frankel, "Antioxidant Activity of Berry Phenolics on Human LowDensity Lipoprotein and Liposome Oxidation," Journal of Agricultural and Food Chemistry, Vol. 46, No. 10, 1998, pp. 4107-4112. doi:10.1021/jf980181c

[6] S. Y. Wang and H. Jiao, "Scavenging Capacity of Berry Crops on Superoxide Radicals, Hydrogen Peroxide, Hydroxyl Radicals, and Singlet Oxygen," Journal of Agricultural and Food Chemistry, Vol. 48, No. 11, 2000, pp. 5677-5684. doi:10.1021/if000766i

[7] F. Shahidi and P. K. J. Wanasundara, "Phenolic Antioxidants," Critical Reviews in Food Science and Nutrition, Vol. 32, No. 1, 1992, pp. 67-103. doi:10.1080/10408399209527581

[8] M. Heinonen, "Antioxidant Activity and Antimicrobial Effect of Berry Phenolics-A Finnish Perspective," Molecular Nutrition and Food Research, Vol. 51, No. 6, 2007, pp. 684-691. doi:10.1002/mnfr.200700006

[9] G. Ruel and C. Couillard, "Evidences of the Cardioprotective Potential of Fruits: The Case of Cranberries," Molecular Nutrition and Food Research, Vol. 51, No. 6, 2007, pp. 692-701. doi:10.1002/mnfr.200600286

[10] M. L. Porter, C. G. Krueger, D. A. Wiebe, D. G. Cunningham and J. D. Reed, "Cranberry Proanthocyanidins Associate with Low-Density Lipoprotein and Inhibit in Vitro $\mathrm{Cu}^{2+}$-Induced Oxidation," Journal of the Science of Food and Agriculture, Vol. 81, No. 14, 2001, pp. 13061313. doi: $10.1002 /$ isfa. 940

[11] C. H. Lee, J. D. Reed and M. P. Richards, "Ability of Various Polyphenolic Classes from Cranberry to Inhibit Lipid Oxidation in Mechanically Separated Turkey and Cooked Ground Pork," Journal of Muscle Foods, Vol. 17, No. 3, 2006, pp. 248-266. doi:10.1111/j.1745-4573.2006.00048.x

[12] V. D. La, J. Labrecque and D. Grenier, "Cytoprotective Effect of Proanthocyanidin-Rich Cranberry Fraction against Bacterial Cell Wall-Mediated Toxicity in Macrophages and Epithelial Cells," Phytotherapy Research, Vol. 23, No. 10, 2009, pp. 1449-1452. doi:10.1002/ptr.2799

[13] S. Huttunen, M. Toivanen, S. Arkko, M. Ruponen and C. Tikkanen-Kaukanen, "Inhibition Activity of Wild Berry Juice Fractions against Streptococcus pneumoniae Binding to Human Bronchial Cells," Phytotherapy Research, Vol. 25, No. 1, 2011, pp. 122-127. doi:10.1002/ptr.3240

[14] N. P. Seeram, L. S. Adams, M. L. Hardy and D. Heber,
"Total Cranberry Extract Versus Its Phytochemical Constituents: Antiproliferative and Synergistic Effects against Human Tumor Cell Lines," Journal of Agricultural and Food Chemistry, Vol. 52, No. 9, 2004, pp. 2512-2517. doi:10.1021/jf0352778

[15] C. C. Neto, C. G. Krueger, T. L. Lamoureaux, M. Kondo, A. J. Vaisberg, R. A. R. Hurta, S. Curtis, M. D. Matchett, H. Yeung, M. I. Sweeney and J. D. Reed, "MALDI-TOF MS Characterization of Proanthocyanidins from Cranberry Fruit (Vaccinium macrocarpon) That Inhibit Tumor Cell Growth and Matrix Metalloproteinase Expression in Vitro," Journal of the Science of Food and Agriculture, Vol. 86, No. 1, 2006, pp. 18-25. doi:10.1002/jsfa.2347

[16] X. Wu and R. L. Prior, "Systematic Identification and Characterization of Anthocyanins by HPLC-ESI-MS-MS in Common Foods in the US-Fruits and Berries," Journal of Agricultural and Food Chemistry, Vol. 53, No. 7, 2005, pp. 2589-2599. doi:10.1021/jf048068b

[17] V. L. Singleton and A. Rossi, "Colorimetry of Total Phenolics with Phosphomolybdic-Phosphotungstic Acid Reagents," American Journal of Enology and Viticulture, Vol. 16, No. 3, 1965, pp. 144-158.

[18] S. Caillet, S., Salmiéri and M. Lacroix, "Evaluation of Free Radical Scavenging Properties of Commercial Grape Phenol Extracts by a Fast Colorimetric Method," Food Chemistry, Vol. 95, No. 1, 2006, pp. 1-8. doi:10.1016/j.foodchem.2004.12.011

[19] S. Caillet, H. Yu, S. Lessard, G. Lamoureux, D. Ajdukovic and M. Lacroix, "Fenton Reaction Applied for Screening Natural Antioxidants," Food Chemistry, Vol. 100 , No. 2, 2007, pp. 542-552. doi:10.1016/j.foodchem.2005.10.009

[20] S. Batzri and E. D. Korn, "Single Bilayer Liposomes Prepared without Sonication," Biochimica et Biophysica Acta, Vol. 298, No. 4, 1973, pp. 1015-1019. doi:10.1016/0005-2736(73)90408-2

[21] J. Côté, S. Caillet, G. Doyon, J. F. Sylvain and M. Lacroix, "Bioactive Compounds in Cranberries and Their Biological Properties," Critical Reviews in Food Science and Nutrition, Vol. 50, No. 7, 2010, pp. 666-679. doi:10.1080/10408390903044107

[22] J. Côté, S. Caillet, G. Doyon, J. F. Sylvain and M. Lacroix, "Analyzing Cranberry Bioactive Compounds," Critical Reviews in Food Science and Nutrition, Vol. 50, No. 9, 2010, pp. 872-888. doi:10.1080/10408390903042069

[23] H. Chen, Y. Zuo and Y. Deng, "Separation and Determination of Flavonoids and Other Phenolic Compounds in Cranberry Juice by High-Performance Liquid Chromatography," Journal of Chromatography, Vol. 913, No. $1-2,2001$, pp. $387-395$. doi:10.1016/S0021-9673(00)01030-X

[24] W. Zheng and S. Y. Wang, "Oxygen Radical Absorbing Capacity of Phenolics in Blueberries, Cranberries, Chokeberries, and Lingonberries," Journal of Agricultural and Food Chemistry, Vol. 51, No. 2, 2003, pp. 502-509. doi:10.1021/jf020728u

[25] S. Ehala, M. Vaher and M. Kaljurand, "Characterization of Phenolic Profiles of Northern European Berries by Ca- 
pillary Electrophoresis and Determination of Their Antioxidant Activity," Journal of Agricultural and Food Chemistry, Vol. 53, No. 16, 2005, pp. 6484-6490. doi:10.1021/jf050397w

[26] A. Bilyk and G. M. Sapers, "Varietal Differences in the Quercetin, Kaempferol, and Myricetin Contents of Highbush Blueberry, Cranberry, and Thornless Blackberry Fruits," Journal of Agricultural and Food Chemistry, Vol. 34, No. 4, 1986, pp. 585-588. doi:10.1021/jf00070a001

[27] Z. Y. Chen, P. T. Chan, K. Y. Ho, K. P. Fung and J. Wang, "Antioxidant Activity of Natural Flavonoids Is Governed by Number and Location of Their Aromatic Hydroxyl Groups," Chemistry and Physics of Lipids, Vol. 79 , No. 2, 1999, pp. 157-163. doi:10.1016/0009-3084(96)02523-6

[28] S. Burda and W. Oleszek, "Antioxidant and Antiradical activities of Flavonoids," Journal of Agricultural and Food Chemistry, Vol. 49, No. 6, 2001, pp. 2774-2779. doi:10.1021/jf001413m

[29] G. Cao, E. Sofic and R. L. Prior, "Antioxidant and Prooxidant Behavior of Flavonoids: Structure-Activity Relationships," Free Radical Biology and Medicine, Vol. 22, No. 5, 1997, pp. 749-760. doi:10.1016/S0891-5849(96)00351-6

[30] C. A. Rice-Evans, N. J. Miller and G. Paganga, "StructureAntioxidant Activity Relationships of Flavonoids and Phenolic Acids," Free Radical Biology and Medicine, Vol. 20, No. 7, 1996, pp. 933-956.

[31] N. Saint-Cricq de Gaulejac, C. Provost and N. Vivas, "Comparative Study of Polyphenol Scavenging Activities Assessed by Different Methods," Journal of Agricultural and Food Chemistry, Vol. 47, No. 2, 1999, pp. 425-431. doi:10.1021/jf980700b

[32] M. Hu, D. J. McClements and E. A. Decker, "Antioxidant Activity of a Proanthocyanidin-Rich Extract from Grape Seed in Whey Protein Isolate Stabilized Algae Oil-inWater Emulsions," Journal of Agricultural and Food Chemistry, Vol. 52, No. 16, 2004, pp. 5272-5276. doi:10.1021/jf049486j

[33] F. M. Steinberg, R. R. Holt, H. H. Schmitz and C. L.
Keen, "Cocoa Procyanidin Chain Length Does Not Determine Ability to Protect LDL from Oxidation When Monomer Units Are Controlled," The Journal of Nutritional Biochemistry, Vol. 13, No. 11, 2002, pp. 645-652. doi:10.1016/S0955-2863(02)00215-2

[34] A. Saija, M. Scalese, M. Lanza, D. Marzullo, F. Bonina and F. Castelli, "Flavonoids as Antioxidant Agents: Importance of Their Interaction with Biomembranes," Free Radical Biology and Medicine, Vol. 19, No. 4, 1995, pp. 481-486. doi:10.1016/0891-5849(94)00240-K

[35] M. Guo, C. Perez, Y. Wei, E. Rapoza, G. Su, F. BouAbdallahb and N. D. Chasteenb, "Iron-Binding Properties of Plant Phenolics and Cranberry's Bio-Effects," Dalton Transactions, Vol. 43, 2007, pp. 4951-4961. doi:10.1039/b705136k

[36] I. Morel, G. Lescoat, P. Cogrel, O. Sergent, N. Pasdeloup, P. Brissot, P. Cillard and J. Cillard, "Antioxidant and Iron-Chelating Activities of the Flavonoids Catechin, Quercetin and Diosmetin on Iron-Loaded Rat Hepatocyte Cultures," Biochemical Pharmacology, Vol. 45, No. 1, 1993, pp. 13-19. doi:10.1016/0006-2952(93)90371-3

[37] J. Laranjinha, L. Almeida and V. Madeira, "Reduction of Ferrylmyoglobin by Dietary Phenolic Acid Derivatives of Cinnamic Acid," Free Radical Biology and Medicine, Vol. 19, No. 3, 1995, pp. 329-337. doi:10.1016/0891-5849(95)00039-Z

[38] N. Yamanaka, O. Oda and S. Nagao, "Prooxidant Activity of Caffeic Acid, Dietary Non-Flavonoid Phenolic Acid, on $\mathrm{Cu}^{2+}$-Induced Low Density Lipoprotein Oxidation," FEBS Letters, Vol. 405, No. 2, 1997, pp. 186-190. doi:10.1016/S0014-5793(97)00185-3

[39] E. J. Borowska, A. Szajdek and S. Czaplicki, "Effect of Heat and Enzyme Treatment on Yield, Phenolic Content and Antioxidant Capacity of Juices from Chokeberry Mash," Italian Journal of Food Science, Vol. 21, No. 2, 2009, pp. 197-209.

[40] A. Szajdek, E. J. Borowska and S. Czaplicki, "Effect of Bilberry Mash Treatment on the Content of Some Biologically Active Compounds and the Antioxidant Activity of Juices," Acta Alimentaria, Vol. 38, No. 3, 2009, pp. 281-292. doi:10.1556/AAlim.38.2009.3.2 